\title{
Alcohols at the Aqueous Surface: Chain Length and Isomer Effects
}

Received 00th January 20xx, Accepted 00th January 20xx DOI: $10.1039 / \times 0 \times x 00000 x$

\author{
M.-M. Walz, ${ }^{a, b,{ }^{*}}$ J. Werner, ${ }^{a, c}$ V. Ekholm, ${ }^{a}$ N. L. Prisle, ${ }^{d}$ G. Öhrwall ${ }^{e}$ and O. Björneholm ${ }^{a}$
}

\begin{abstract}
Surface-active organic molecules at the liquid-vapor interface are of great importance in atmospheric science. Therefore, we studied the surface behavior of alcohol isomers with different chain lengths (C4-C6) in aqueous solution with surfaceand chemically sensitive X-ray photoelectron spectroscopy (XPS), which reveals information about the surface structure on a molecular level. Gibbs free energies of adsorption and surface concentrations are determined from the XPS results using a standard Langmuir adsorption isotherm model. The free energies of adsorption, ranging from around $-15 \mathrm{to}-19 \mathrm{~kJ} / \mathrm{mol}$ (C4-C6), scale linearly with the number of carbon atoms within the alcohols with $\Delta \mathrm{G}_{\mathrm{Ads}}$ per $-\mathrm{CH}_{2}-\approx-2 \mathrm{~kJ} / \mathrm{mol}$. While for the linear alcohols, surface concentrations lie around $2.4 \times 10^{14}$ molecules $/ \mathrm{cm}^{2}$ at the bulk concentrations where monolayers are formed, the studied branched alcohols show lower surface concentrations of around $1.6 \times 10^{14} \mathrm{molecules} / \mathrm{cm}^{2}$, both of which are in line with the molecular structure and their orientation at the interface. Interestingly, we find that there is a maximum in the surface enrichment factor for linear alcohols at low concentrations, which is not observed for the shorter branched alcohols. This is interpreted in terms of a cooperative effect, which we suggest to be the result of more effective van der Waals interactions between the linear alcohol alkyl chains at the aqueous surface, making it energetically even more favorable to reside at the liquid-vapor interface.
\end{abstract}

\section{Introduction}

Atmospheric organic aerosols form from less volatile oxidation products of volatile precursors, either by new particle formation or by condensation into a pre-existing aerosol phase. ${ }^{1,2}$ A large number of aerosol precursors have been identified globally and their oxidation pathways are highly sensitive to the atmospheric environment and ambient conditions, leading to a suite of different oxidation products with similar functionalities and varying molecular structures, such as positional isomers. ${ }^{3,4}$ Such structural variations may in turn lead to very different molecular properties, such as vapor pressures and aqueous phase mixing interactions, which are crucial to their aerosol-forming potential. ${ }^{5}$ Therefore, studying the variation of properties of organic compounds with similar functionalities and different molecular structures, and

\footnotetext{
a. Uppsala University, Department of Physics and Astronomy, Box 516, 75120 Uppsala, Sweden.*marie-madeleine.walz@physics.uu.se

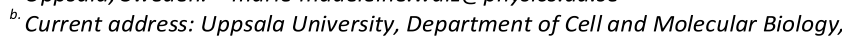
Box 596, 75124 Uppsala, Sweden.

c. Swedish University of Agricultural Sciences, Department of Chemistry and Biotechnology, Box 7015, 75007 Uppsala, Sweden.

d. Department of Physics, Helsinki University, Box 64, 00014 Helsinki University, Finland.

e. MAX IV Laboratory, Lund University, Box 118, 22100 Lund, Sweden.

Electronic Supplementary Information (ESI) available: [Fig. S1 Change of binding energy splitting, Table S1 $\mathrm{N}_{\mathrm{s}, \max }$ values, Table $\mathrm{S} 2 \mathrm{c}_{\mathrm{surface}}$ in $\mathrm{mol} / \mathrm{m}^{2}$ ]. See DOI: $10.1039 / x 0 x \times 00000 x$
}

ultimately their mixtures, is of high importance for improving our understanding of atmospheric organic aerosols, which are relevant for the global radiation budget and cloud formation. Still, the major uncertainty in the total radiative forcing estimates, which constitute a crucial element of climate prediction, are aerosol effects. ${ }^{6,7}$

Especially, the surface behavior of amphiphilic organic molecules is of key interest for a better understanding of atmospheric aerosols, due to the high surface-to-bulk ratios of these nanometer- to micrometer-sized airborne particles. The surface and its chemical composition may potentially alter their physico-chemical interfacial properties. In particular evaporation and condensation processes may be affected, which are important for cloud formation and growth, as discussed earlier in more detail. ${ }^{8}$

In this study, we focus on short-chained alcohols and compare alcohol isomers of different chain lengths (C4-C6). Such surface-active short-chained oxygenated compounds compose a large fraction of the organic compounds found in tropospheric aerosols. ${ }^{9}$ As with most other atmospheric organic compounds, the surface structure of short-chained alcohols in aqueous solution in general is not yet well understood. ${ }^{10,11}$ The importance of alcohol functional groups at the liquid-vapor interface is specifically motivated by the newly found extremely low-volatility organic compounds, ELVOCs, which are hypothesized to make a crucial contribution to the "missing secondary organic aerosol" mystery, ${ }^{12}$ as well 
as humic-like substances (HULIS) ${ }^{13}$. Both, ELVOCs and HULIS, are believed to contain significant alcohol functionality. These highly complex molecules are however too difficult to study immediately, and the simpler alcohols provide a valuable intermediate step, as their spectra are easier to interpret and their physico-chemical properties are much better constrained.

Such surface-active organic compounds accumulate at the liquid-vapor interface, and may as a consequence alter the surface properties, such as lower the surface tension. As for example observed for alcohol-water solutions, the surface tension at a given concentration decreases with respect to pure water with increasing alkyl chain length, ${ }^{14}$ and comparing linear and non-linear isomers, higher monolayer surface excess and smaller surface areas per molecule are observed for longer linear alcohol isomers in comparison to branched ones (heptanol to dodecanol, C7-C12). ${ }^{15}$ This example indicates that chemistry occurring on the surfaces of aerosol droplets is in general affected by the organic content, and the respective behavior of the organic molecules at the droplet-air interface. ${ }^{16-19}$ The comparison of different alcohols is of great interest as it is not certain that all compounds with the same functional group will act and interact in the same way. It is for example well known that physical properties may alternate with the chain length, e.g. in terms of an even-odd alteration. ${ }^{20}$ Furthermore, the study and comparison of different isomers is of general interest as in atmospheric oxidation reactions position isomerism is ubiquitous, ${ }^{21,22}$ and such isomers can have very different physical and chemical properties. ${ }^{23,24}$

The alcohols at the aqueous surface were studied with surface- and chemically sensitive $X$-ray photoelectron spectroscopy (XPS), which is commonly applied in solid-state physics. XPS is not only element-sensitive but also sensitive to the formal oxidation state of an atom and its local chemical and physical environment, in this study specifically to the interaction of the solute with water and other amphiphiles. This information is reflected in the binding energy and the intensity of the core-level photoelectrons. Due to the short effective attenuation length of the photoelectrons at the experimental conditions used here, the photoelectron signal primarily originates from within a few nanometers of the surface and is thus strongly dependent on the concentration, orientation and organization of molecules at the liquid-vapor interface.

\section{Experimental}

All XPS experiments were performed at MAX-lab, Lund, Sweden at the 1411 undulator beamline. ${ }^{25}$ To perform XPS at the aqueous surface, a liquid micro-jet set-up was applied. Details on this technique can be found e.g. in reference ${ }^{26}$.

The liquid micro-jet $(\varnothing \approx 20 \mu \mathrm{m}$, flow rate $\approx 0.5 \mathrm{ml} / \mathrm{min}(\approx$ $26.5 \mathrm{~m} / \mathrm{s}$ ), $\mathrm{T} \approx 283 \mathrm{~K}$ ) is injected through a glass nozzle into an evacuated analysis chamber. Photoionization by linearly polarized synchrotron light occurs at approx. $1 \mathrm{~mm}$ after the injection point, before the liquid jet breaks up into droplets and is frozen out in a cold trap. The photoelectrons are detected by a hemispherical electron energy analyzer (Scienta R4000) mounted perpendicular to the propagation direction of the liquid jet, at $54.7^{\circ}$ relative to the polarization plane of the synchrotron light to minimize angular distribution effects. ${ }^{27}$ The total experimental resolution at the applied photon energy, $E_{\text {Photon }}=360 \mathrm{eV}$, is lower than $0.3 \mathrm{eV}$, as determined from the width of the water gas phase valence band $1 b_{1}$ state. All spectra were energy-calibrated against the binding energy of the $1 b_{1}$ state $(\mathrm{HOMO})$ of liquid water $\left(\mathrm{E}_{\mathrm{B}}\left(1 \mathrm{~b}_{1}\right.\right.$, liquid water) $=11.16 \mathrm{eV})^{28}$ and intensity-normalized (against photon flux and acquisition time). In order to facilitate the comparison of different experimental runs and to monitor the stability of the measurements, the $1 b_{1}$ valence band state of liquid water of an aqueous sodium chloride solution $(50 \mathrm{mM})$ was measured between all alcohol solutions and used as an internal intensity reference. The intensities of these reference measurements were constant within $\pm 5-10 \%$.

Aqueous solutions of 1-butanol, tert-butanol, 1-pentanol, 3-pentanol, 1-hexanol and 3-hexanol (purities > $99 \%$, Sigma Aldrich) were prepared from de-ionized water (Millipore Direct-Q, resistivity $>18.2 \mathrm{M} \Omega \mathrm{cm}$ ). To avoid charging of the liquid jet due to photoionization and electrokinetic charging, ${ }^{29}$ all solutions contained $25 \mathrm{mM}$ sodium chloride (purity $99 \%$, Sigma Aldrich).

The amphiphiles at the interface were monitored via the $C$ $1 \mathrm{~s}$ signal using $\mathrm{E}_{\text {photon }}=360 \mathrm{eV}$. At this photon energy, the $\mathrm{C} 1 \mathrm{~s}$ photoelectrons have a kinetic energy of approximately $70 \mathrm{eV}$, making the XPS measurements highly surface-sensitive, ${ }^{27}$ as the effective attenuation length is estimated to be in the order of $1 \mathrm{~nm} .^{30,31}$ The photoelectron spectra were fitted with a least-squares method, using two symmetric Voigt line profiles for the liquid phase signal and four asymmetric $\mathrm{PCl}^{32}$ line profiles for the gas phase signal from the respective solute to model vibrational broadening. The lifetime width for $C$ is core holes corresponding to the Lorentzian width was set to 0.1 $\mathrm{eV} .^{33}$ Gaussian widths were free parameters, but linked such that they were the same for the corresponding peaks in all spectra. Energy positions and intensities were also free parameters. The contributing gas phase signal of the solute was fitted by linking the energy splitting and the intensity ratio to its "pure" gas phase spectrum. Such a gas phase spectrum was recorded with the liquid jet lowered out of the X-ray beam, thus only containing contributions from the vapor phase.

\section{Results and discussion}

\section{Surface coverage and orientation of the molecules}

In Fig. 1, a C 1s XPS spectrum of 3-hexanol ( $25 \mathrm{mM}$ ) in aqueous solution is shown with the fit of the liquid phase signal as a representative spectrum for the studied alcohols in aqueous solution. All studied alcohols in aqueous solutions are characterized by two $C$ 1s peaks. The peak at lower binding energy $(<290 \mathrm{eV})$ originates from the carbons in the alkyl chain $\left(C_{C}\right)$, while the peak at higher binding energy (> $291 \mathrm{eV}$ ) can be assigned to the carbon atom to which the hydroxyl 


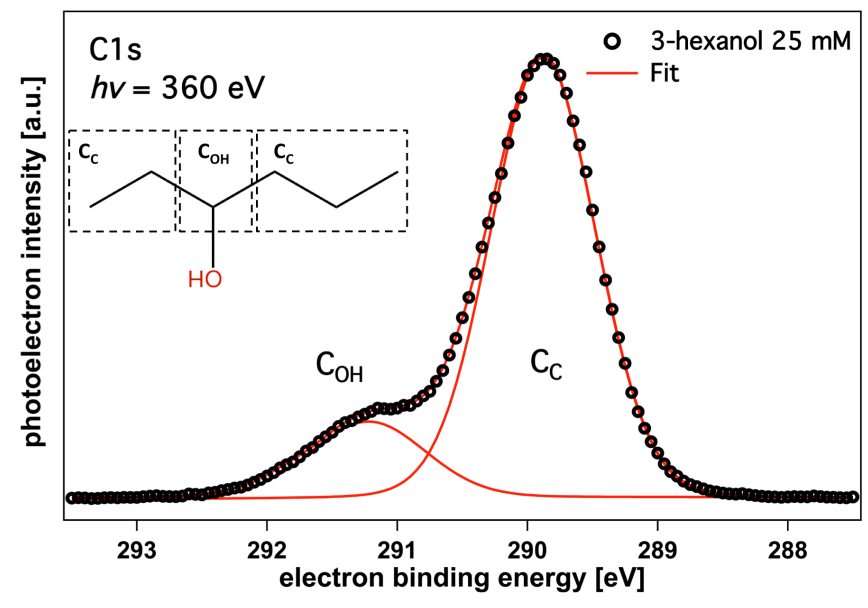

Fig. $1 \mathrm{C}$ 1s XPS spectrum of 3-hexanol in aqueous solution ( $25 \mathrm{mM}$ ) acquired with a photon energy of $E_{\text {photon }}=360 \mathrm{eV}$, shown with the respective fit of the liquid phase signal $\left(\mathrm{C}_{\mathrm{C}}\right.$ and $\mathrm{C}_{\mathrm{OH}}$, see skeletal formula inset). The fit of the gas phase is not shown.

group is directly attached $\left(\mathrm{C}_{\mathrm{OH}}\right)$. The higher electron binding energy of $\mathrm{C}_{\mathrm{OH}} 1 \mathrm{~s}$ compared to $\mathrm{C}_{\mathrm{C}} 1 \mathrm{~s}$ is due to a reduced electron density at the $\mathrm{C}_{\mathrm{OH}}$ as the attached hydroxyl group is electron-withdrawing. The resulting decreased shielding of the nucleus causes the $\mathrm{C}_{\mathrm{OH}}$ 1s electrons to be more tightly bound. The $C$ 1s signal from the liquid phase of the solute is shifted to lower binding energies (by roughly $0.6 \mathrm{eV}$ ) compared to the corresponding signal from the gas phase (fit not shown). The gas phase signal can be observed as a very small shoulder towards higher binding energies. The lower binding energies of the alcohols in solution are primarily due to polarization screening of the charged $C$ 1s core-hole final state by the water molecules. $^{34}$

A concentration-dependent study was performed on several different alcohols (1-butanol, tert-butanol, 1-pentanol, 3-pentanol, 1-hexanol and 3-hexanol), in order to study variations in their adsorption behavior at the liquid-vapor interface with changes in molecular structure and individual concentration. All acquired spectra were evaluated regarding the total area $A_{\text {tot }}$ of the liquid phase $C$ 1s photoelectron (PE) signal $\left(A_{\text {tot }}=A\left(C_{C}\right)+A\left(C_{O H}\right)\right)$ and the $P E$ intensity ratio $R$ between the two liquid phase $C 1$ s peak areas $\left(R=A\left(C_{C}\right)\right.$ / $A\left(C_{O H}\right)$ ). As discussed in more detail before, ${ }^{35}$ the PE signal $A_{\text {tot }}$ can be used as a measure for the amount of solutes at the solution interface, while the PE intensity ratio $\mathrm{R}$ between the peak areas of $\mathrm{C}_{\mathrm{C}}$ and $\mathrm{C}_{\mathrm{OH}}$ reveals information about the orientation of these molecules in the surface region. The binding energy is sensitive to their local chemical and physical environment, i.e. to their interaction with water and each other. This aspect was covered in detail in our previous paper. ${ }^{35}$ The change in binding energy splitting for all alcohols investigated in this paper can be found in the SI.

The results of the concentration-dependent study are depicted in Fig. 2, where in panel a, the $y$-axis is the total $C$ is $\mathrm{PE}$ signal, $A_{\text {tot }}$, and in panel $b$, it is the PE intensity ratio $R$. The trend of the total PE signal with increasing concentration (see

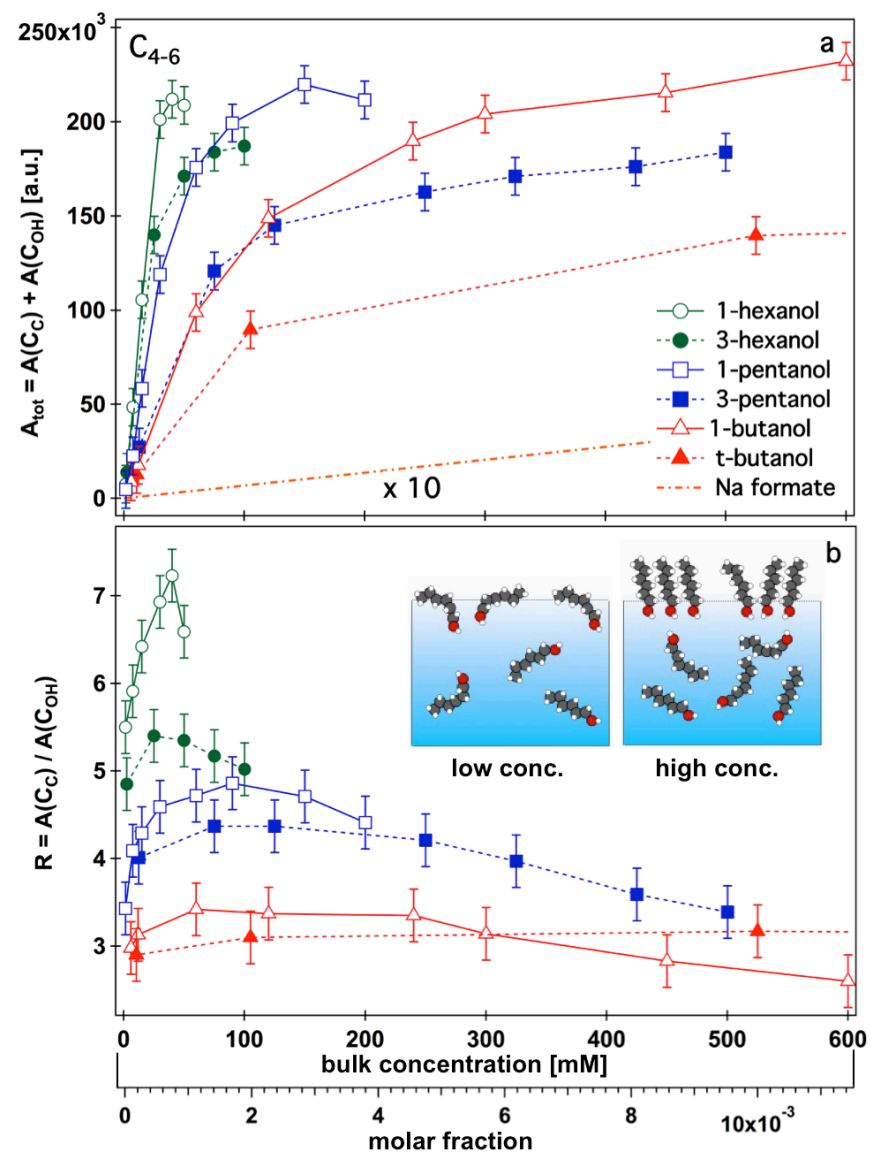

Fig. 2 Results of C 1s XPS spectra for the different alcohols in aqueous solution at different concentrations: (a) Total area of the liquid phase $C$ 1s photoelectron signal $\left(A_{\text {tot }}\right)$. Error bars are estimated from variations in intensity stability. (b) Ratio between the liquid phase $\mathrm{C}_{\mathrm{C}}$ and $\mathrm{C}_{\mathrm{OH}}$ signal (R). Error bars indicate the range of values obtained by different fitting approaches. The inset shows, conceptually, the surface behavior of the alcohols at low and high concentration.

Fig. 2a) is comparable for all alcohols and resembles a Langmuir adsorption isotherm. ${ }^{36}$

The trend of the curve can be divided into two regions, based on the change in the slope. In the first region, the PE signal increases nearly linearly with concentration, whereas in the second region, no further significant increase in the PE intensity can be observed, i.e. $A_{\text {tot }}$ saturates. As discussed earlier, ${ }^{35}$ the trend of the curve can be interpreted as a result of the adsorption of alcohols at the aqueous surface with increasing bulk concentration and, finally, the formation of a monolayer-like structure (ML) in the surface region. Here, the term monolayer refers to a closely packed layer of amphiphilic molecules at the liquid-vapor interface that has approximately a thickness of a single molecular length, i.e. with the molecules having an orientation roughly vertical to the interface.

In general, it is observed that $A_{\text {tot }}$ of all the linear alcohols (1-butanol, 1-pentanol and 1-hexanol) is higher at any concentration than the corresponding signal for the branched alcohols (tert-butanol, 3-pentanol and 3-hexanol). This indicates that at any concentration there are more linear alcohol molecules than branched alcohols in the immediate 
surface region (comparing the respective isomer pairs, e.g. 1hexanol vs. 3-hexanol etc.). At ML coverage this also means that the linear alcohols have a higher molecular packing density, which can be explained by steric effects: the bulkier secondary / tertiary alcohols require more space than the primary alcohols. This phenomenon is in line with a study on longer alcohol isomers from heptanol to dodecanol. ${ }^{15}$ In Fig. 2 a, also the photoelectron signal for sodium formate solutions is indicated (dotted orange line, multiplied by a factor of 10 ). This signal corresponds to the anion formate, i.e. just one carbon atom, which is assumed to be depleted from the surface. ${ }^{37}$ Both the lower number of carbon atoms and the lower surface prevalence, explain the lower intensity of the formate signal in comparison to the alcohols. The formate signal is used as a reference bulk signal for further evaluation (see below).

In Fig. $2 \mathrm{~b}$, the $\mathrm{PE}$ intensity ratio $\mathrm{R}$ between the two $\mathrm{C} 1 \mathrm{~s}$ peak areas $\left(\mathrm{C}_{\mathrm{C}} / \mathrm{C}_{\mathrm{OH}}\right)$ is plotted versus the alcohol bulk concentration. As for $A_{\text {tot }}$, two regions are observed; first, $R$ increases up to the concentration where a $\mathrm{ML}$ is formed $\left(\mathrm{c}_{\mathrm{ML}}\right)$, then it decreases again. This effect is more pronounced for the linear alcohols, which is discussed in more detail below. These two regions coincide with the ones similarly observed for the Langmuir-like curve, shown in Fig. 2a. Note that the exact values of $\mathrm{R}$ depend on the applied spectral fitting procedure, while the general trend is always observed.

Assuming that possible modulations of the photoionization cross-section of $\mathrm{C}_{\mathrm{C}}$ and $\mathrm{C}_{\mathrm{OH}}$ is negligible ${ }^{38}$ and that the solutes are randomly or parallel oriented at the interface, one expects a ratio which is close to the stoichiometric ratio, i.e. 3 for butanol (3:1), 4 for pentanol (4:1) and 5 for hexanol (5:1). A deviation from this ratio, on the other hand, indicates that the amphiphiles change their orientation at the liquid-vapor interface. The observed ratios, which increase from lower concentration up to $\mathrm{C}_{\mathrm{ML}}$, thus indicate that the signal from $\mathrm{C}_{\mathrm{OH}}$ is progressively dampened as the molecules gradually "stand up" (see inset in Fig. 2b), with their alkyl chains pointing towards the vapor phase, resulting in $\mathrm{R}>$ stoichiometric ratio. At very low concentrations, where the alcohols at the aqueous surface interact mainly with water molecules, the alkyl chains are oriented "parallel" to the aqueous surface which is in line with the observed ratios that are close to the stoichiometric ratios, i.e. all carbon atoms contribute equally to the acquired $C$ 1s signal. At higher concentrations, more and more amphiphiles accumulate at the aqueous surface and interact with each other. At surface coverage close to one $M L$, the amphiphilic molecules have a preferential orientation such that the hydrophilic hydroxyl groups are immersed into the aqueous phase maintaining hydrogen bonds with water, while the hydrophobic alkyl chains are pointing out of the solution phase being partially dehydrated which was confirmed by MD simulations earlier. ${ }^{35}$ This preferential orientation of the amphiphilic molecules is proposed to be driven by hydrophobic / hydrophilic interactions of the amphiphiles with the solvent water and by van der Waals interactions between the alkyl chains to oppose the loss of entropy. In general, the linear alcohols have a higher ratio (i.e. more deviating from the stoichiometric ratio) at $\mathrm{ML}$ coverage than the branched alcohols. These larger ratios for the primary alcohols indicate an enhancement of the $C_{c} 1 s$ PE signal and a dampening of the $\mathrm{C}_{\mathrm{OH}}$ 1s PE signal by the longer alkyl chains in comparison to the branched isomers, which is in line with the observed orientation and the molecular dimensions. At concentrations higher than $\mathrm{C}_{\mathrm{ML}}, \mathrm{R}$ decreases for all isomers. It is suggested that this decline can be explained by the contributing signal from the surface-near-bulk region in which the molecules are more randomly oriented. ${ }^{35}$ We can thus conclude that the bulk concentration where a monolayer starts to form, $\mathrm{C}_{\mathrm{ML}}$, is around $40 \pm 10 \mathrm{mM}$ for hexanol, around $100 \pm 20 \mathrm{mM}$ for pentanol and around $200 \pm 40 \mathrm{mM}$ for butanol.

\section{Langmuir isotherm model}

In order to determine the surface coverage and the surface concentration of the alcohols at the aqueous surface, as well as to estimate the Gibbs free energy of adsorption, $\Delta G_{A d s}$, a standard Langmuir adsorption model is used to fit the data. ${ }^{39-}$ 41

$$
N_{S}=\frac{N_{S, \text { max }} x_{\text {bulk }}}{x_{\text {bulk }}+\left(1-x_{\text {bulk }}\right) \exp \left(\frac{\Delta G_{A d s}}{R T}\right)}
$$

Both, $N_{S}$ and $N_{S \text {, max }}$ are given in arbitrary units as $N_{S}$ is the surface contribution of the recorded PE signal. $\mathrm{N}_{\mathrm{S}}$ scales with the surface concentration of the solute, i.e. the number of molecules in the probed volume, and $\mathrm{N}_{\mathrm{s} \text {, max }}$ is directly proportional to the maximum possible concentration, i.e. the concentration of the pure compound (for further discussion, see below). $x_{\text {bulk }}$ is the molar fraction of the solute in the bulk and $\left(1-x_{\text {bulk }}\right)$ is thus equal to the bulk-water molar fraction. The Langmuir model assumes, beyond other assumptions, that there is monolayer adsorption and no interaction between the adsorbates. In order to calculate a signal, which is directly proportional to the surface concentration $N_{s}$, from the recorded photoelectron signal $A_{\text {tot }}$ (see Fig. 2 a), the signal $A_{\text {tot }}$ is divided by the number of carbon atoms in the corresponding molecule and a bulk signal (approximated by means of a reference measurement on sodium formate, see above $)^{8,35}$ is subtracted. Linking the surface signal directly to the surface concentration has certain limitations for longer alkyl chain lengths as the photoemission signal is then more attenuated upon a change in orientation of the molecules. For the presented data, however, this seems still to be in an acceptable range as the determined surface concentrations and molecular areas are in good agreement with other literature that applies more conventional methods such as surface tension measurements (for more details, see below).

In Fig. 3, the corresponding Langmuir fits are shown. The data points are fitted well, especially for the branched alcohols. However, one might notice that in particular for the linear alcohols at lower concentrations, there is an overestimation of the surface concentrations by the Langmuir model, which is a direct result of fitting the surface 

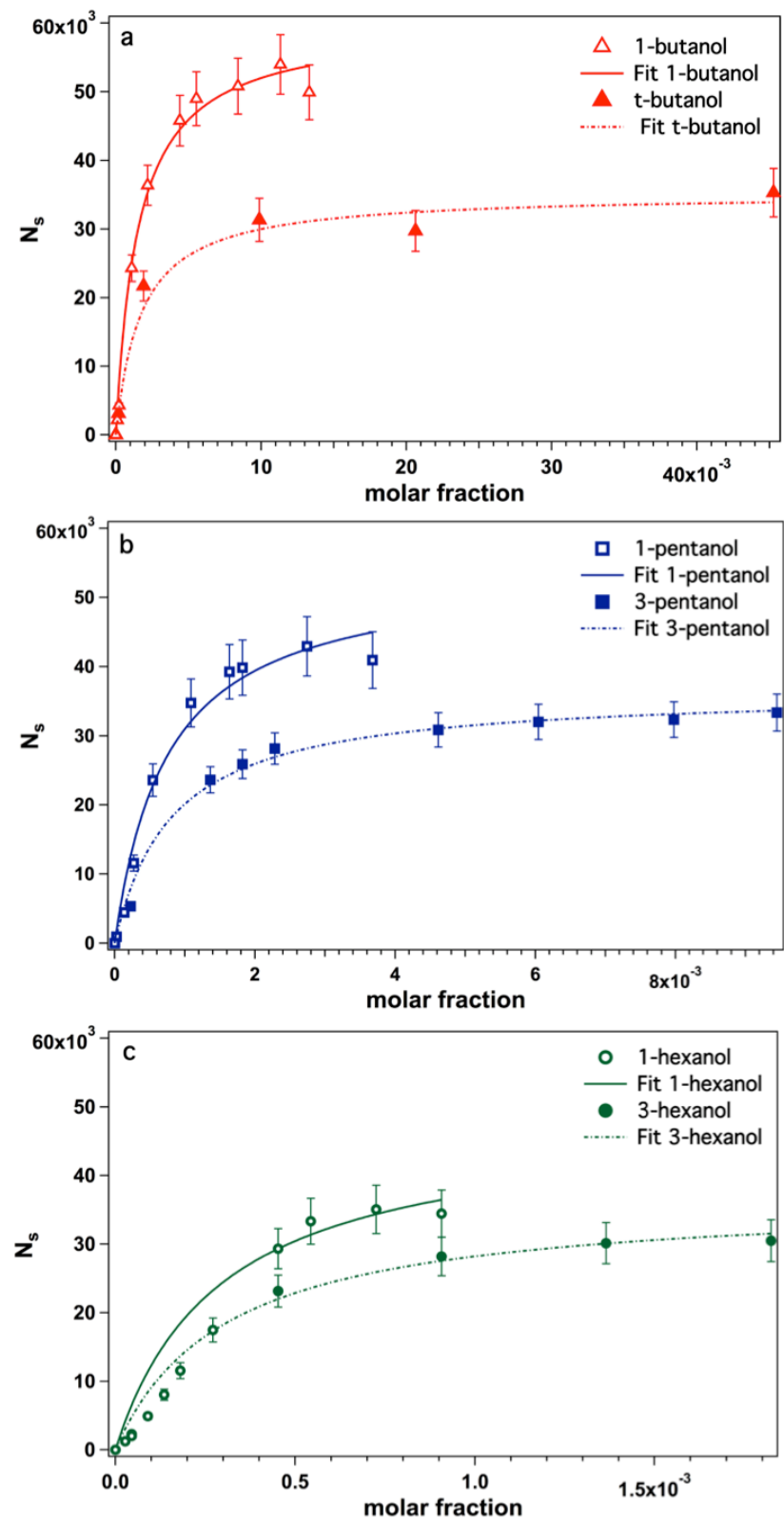

Fig. 3 Surface concentration $\mathrm{N}_{\mathrm{s}}$ (in arbitrary units) versus the solute bulk molar fraction $x_{\text {bulk }}$ with the respective Langmuir fits. (a) 1- and tert-butanol, (b) 1- and 3-pentanol, and (c) 1- and 3-hexanol. The error bars are estimated from experimental uncertainties.

concentrations at higher concentrations more accurately, i.e. in order not to overestimate $\mathrm{N}_{s, \max }$. This deviation gets more pronounced with increasing alkyl chain length (see e.g. Fig. 3c, 1-hexanol). We will discuss this phenomenon in more detail in the section Surface enrichment factor.

The values of $\Delta G_{A d s}$ for the alcohols, adsorbing at the liquid-vapor interface from the bulk solution, were estimated with the Langmuir model. For the different alcohols, $\Delta G_{\text {Ads }}$ scales linearly with the number of carbon atoms within the molecule and were determined to be around $-15 \mathrm{~kJ} / \mathrm{mol}$ for butanol, $-17 \mathrm{~kJ} / \mathrm{mol}$ for pentanol and $-19 \mathrm{~kJ} / \mathrm{mol}$ for hexanol (Table 1), resulting in a $\Delta \mathrm{G}_{\text {Ads }}$ per $-\mathrm{CH}_{2}-\approx-2 \mathrm{~kJ} / \mathrm{mol}$. This is in

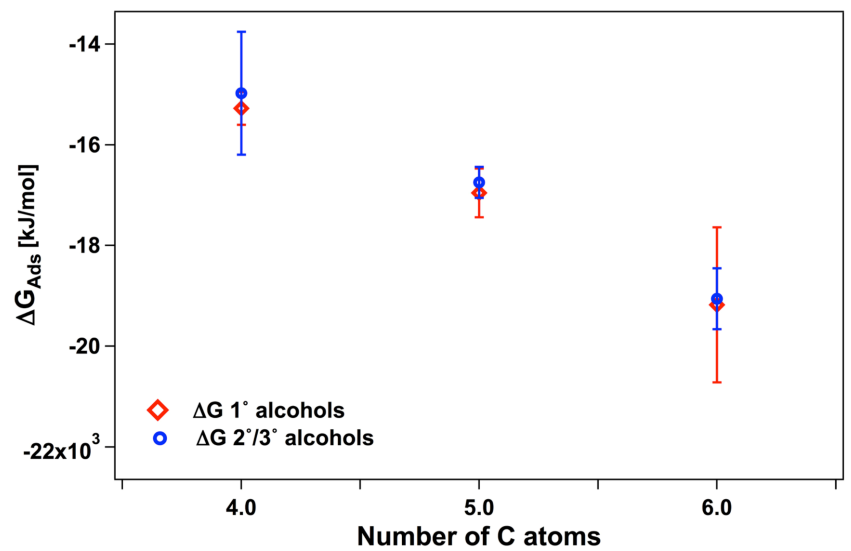

Fig. 4 Gibbs free energies of adsorption $\Delta G_{A d s}$ in $\mathrm{kJ} / \mathrm{mol}$ for the different alcohols in aqueous solution plotted versus the number of carbon atoms. The error bars are given in Table 1 and correspond to one standard deviation based on the Langmuir fit.

Table 1 Gibbs free energies of adsorption $\Delta \mathrm{G}_{\mathrm{Ads}}$ for the different alcohols in $\mathrm{kJ} / \mathrm{mol}$

\begin{tabular}{llll}
\hline molecule & $\Delta \mathrm{G}_{\mathrm{Ads}}(\mathrm{kJ} / \mathrm{mol})$ & molecule & $\Delta \mathrm{G}_{\mathrm{Ads}}(\mathrm{kJ} / \mathrm{mol})$ \\
\hline 1-butanol & $-15.3 \pm 0.3$ & tert-butanol & $-15.0 \pm 1.2$ \\
1-pentanol & $-17.0 \pm 0.5$ & 3-pentanol & $-16.7 \pm 0.3$ \\
1-hexanol & $-19.2 \pm 1.5$ & 3-hexanol & $-19.1 \pm 0.6$
\end{tabular}

line with Danov and Kralchevsky who determined a $\Delta \mathrm{G}_{\mathrm{Ads}}$ value of $-2.5 \mathrm{~kJ} / \mathrm{mol}$ per $-\mathrm{CH}_{2}$ - for primary alcohols adsorbing at the water-air interface. ${ }^{42}$ By means of this value, one can extrapolate $\Delta G_{\text {Ads }}$ values, for example for shorter chain lengths, such as ethanol (C2) predicting a $\Delta G_{A d s}$ value of around $-11 \mathrm{~kJ} / \mathrm{mol}$, which was confirmed experimentally by XPS measurements. ${ }^{43}$ The determined $\Delta G_{\text {Ads }}$ value for ethanol is in line with other literature. ${ }^{44}$ The linear trend of $\Delta G_{\text {Ads }}$ versus the number of carbon atoms is visualized in Fig. 4. It is noticed that in general the $\Delta \mathrm{G}_{\mathrm{Ads}}$ values for the linear alcohols are slightly more negative compared to the branched alcohols, which is in line with their higher surface concentrations, although this is within the margin of the error bars.

\section{Surface coverage, surface concentration and molecular area}

By means of the measured $\mathrm{N}_{\mathrm{S}}$ and the determined $\mathrm{N}_{\mathrm{S} \text {, max }}$ values (see $\mathrm{SI}$ ), the surface coverage $\theta$ (with values from 0 to 1 ) can be calculated with $\theta=\mathrm{N}_{\mathrm{S}} / \mathrm{N}_{\mathrm{s}, \max }$. In Fig. 5 , the calculated surface coverage $\theta$ for the studied alcohols is plotted versus the alcohol bulk concentration. For the different isomer pairs, the same trend, i.e. a similar surface coverage at any concentration is observed, which suggests that this quantity is related to the number of carbon atoms in the molecule itself. In general, the surface coverage saturates around $0.8-0.9$, which reveals that at the experimentally observed maximum surface coverage there are still water molecules incorporated into the surface region that is saturated with alcohol molecules.

In the following part, the molar surface concentration, $\mathrm{C}_{\text {surface, }}$ in $\mathrm{mol} / \mathrm{l}$ is estimated. From the Langmuir fitting 


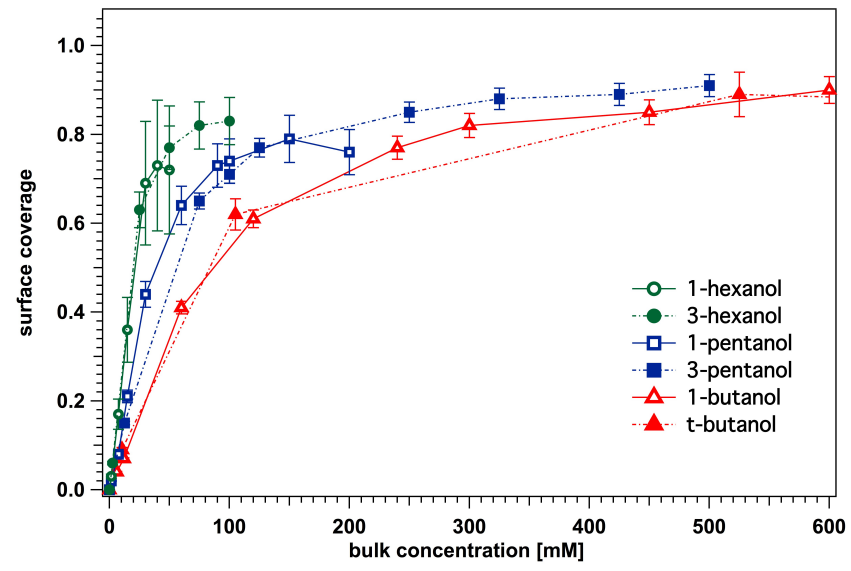

Fig. 5 Surface coverage $\theta$ for the different alcohols versus their bulk concentration. The error bars result from the uncertainty in $\mathrm{N}_{\mathrm{s} \text {, max }}$ given by one standard deviation based on the Langmuir fit (compare Table S1 in the supporting information).

equation, it is clear that $N_{S}$ will be equal to $N_{S, \max }$ when the molar bulk fraction, $x_{\text {bulk, }}$ is equal to 1 , i.e. for the pure compound. Thus one can determine the molar surface concentration by multiplying the surface coverage $\theta$ with the maximum possible concentration, i.e. the concentration of the pure compound (listed in Table 2), using $c_{\text {surface }}=\theta c_{\max }$. In Fig. 6 , the calculated molar surface concentration for the various alcohol isomers is plotted versus the respective bulk concentration. It can be seen, that the different pairs of isomers seem to have similar trends, as observed for the surface coverages. From $\mathrm{C} 4$ to $\mathrm{C} 6$, the maximum molar surface concentration decreases, from around $9 \mathrm{M}$ to around $6 \mathrm{M}$. This reflects the fact that the larger molecules require more space than the smaller ones, as a constant volume of the surface is considered. Again one can see that all maximum experimentally observed molar concentrations are lower than the concentrations for the pure compounds, confirming that water is incorporated into the monolayer.

From the molar surface concentration, one can estimate the "surface molecular volume", i.e. the volume at the surface, which is required by one alcohol molecule plus the surrounding water molecules at ML coverage. For this we assume that all organic molecules in the probed volume are located directly at the interface, i.e. the molecular length determines the thickness of the monolayer. Thus, by dividing the "surface molecular volume" by the molecular length, the molecular area of the different alcohols can be estimated (for more details, see $\mathrm{SI}$ ). The resulting molecular areas at $\mathrm{ML}$ coverage are summarized in Table 3 . For comparison, the molecular areas at $\mathrm{N}_{\mathrm{s} \text {, max }}$ are also calculated. Here, no water is incorporated into the surface layer as these values correspond to the pure compounds.

In line with the larger $\mathrm{N}_{\mathrm{s} \text {, max }}$ values for linear alcohols compared to the branched alcohols, we find for the linear alcohols at the $\mathrm{ML}$ concentration that molecular areas range from $39-44 \pm 2 \AA^{2} /$ molecule for C4 - C6, while the molecular areas for the branched alcohols are around $60-68 \pm 2$ $\AA^{2} /$ molecule. The given error for the molecular areas

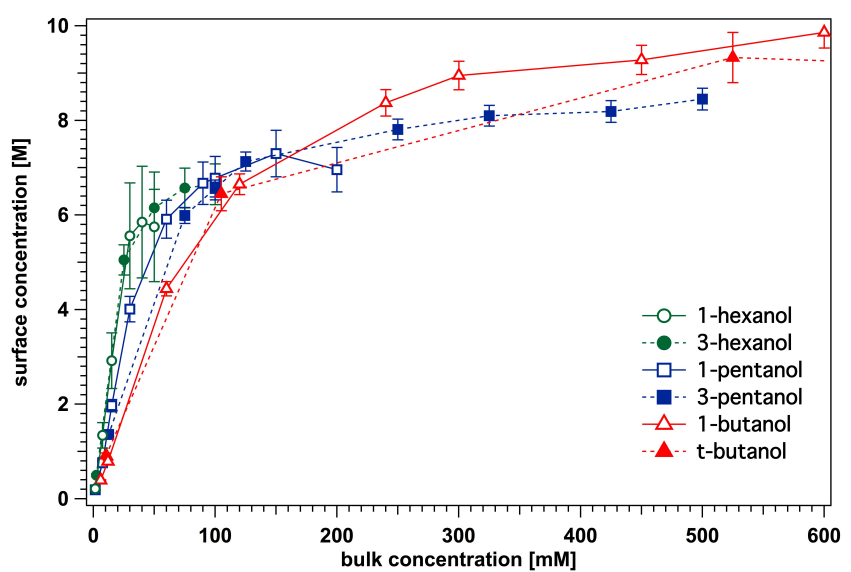

Fig. 6 Molar surface concentration, $c_{\text {surface, }}(\mathrm{mol} / \mathrm{l})$ for the different alcohols versus the bulk concentration, $c_{\text {bulk }}(\mathrm{mmol} / \mathrm{l})$. The error bars result from the uncertainty in $\mathrm{N}_{\mathrm{s} \text {, max }}$ given by one standard deviation based on the Langmuir fit.

Table 2 Molar concentrations for the pure compounds in $\mathrm{mol} / \mathrm{l}$

\begin{tabular}{llll} 
molecule & $\mathrm{c}_{\max }(\mathrm{mol} / \mathrm{I})$ & molecule & $\mathrm{c}_{\max }(\mathrm{mol} / \mathrm{l})$ \\
\hline 1-butanol & 10.9 & tert-butanol & 10.5 \\
1-pentanol & 9.2 & 3-pentanol & 9.3 \\
1-hexanol & 8.0 & 3-hexanol & 8.0
\end{tabular}

Table 3 Molecular areas at ML coverage $\left(A_{M L}\right)$ for different alcohols at the aqueous surface and minimum molecular areas $\left(A_{N(s, m a x)}\right)$ corresponding to $\mathrm{N}_{\mathrm{s} \text {, max }}$ calculated from the pure compounds (see Table 2).

$\begin{array}{llll}\text { molecule } & \text { length }(\AA) & \mathrm{A}_{M L}\left(\AA^{2}\right) & \mathrm{A}_{N(\mathrm{~s}, \max )}\left(\AA^{2}\right) \\ \text { 1-butanol } & \approx 5.5 & 39 \pm 2 & 28 \pm 2 \\ \text { 1-pentanol } & \approx 6.0 & 41 \pm 2 & 30 \pm 2 \\ \text { 1-hexanol } & \approx 6.5 & 44 \pm 2 & 32 \pm 2 \\ \text { tert-butanol } & \approx 3.5 & 68 \pm 2 & 45 \pm 2 \\ \text { 3-pentanol } & \approx 4.0 & 63 \pm 2 & 45 \pm 2 \\ \text { 3-hexanol } & \approx 4.5 & 60 \pm 2 & 46 \pm 2\end{array}$

( $\pm 2 \AA^{2} /$ molecule) is estimated from the uncertainty in the molecular length, which is assumed to be $\pm 0.5 \AA$ (depending on the exact orientation and conformation of the molecules at $\mathrm{ML}$ coverage). In contrast to these molecular areas at $\mathrm{c}_{\mathrm{ML}}$, the calculated values at $N_{S, \text { max }}$ are around $30 \pm 2 \AA^{2} /$ molecule for the linear alcohols and around $45 \pm 2 \AA^{2}$ /molecule for the branched alcohols. The difference in the molecular areas between linear and branched alcohols is in good agreement with values reported elsewhere. ${ }^{15}$

From the molecular areas, the surface concentration in molecules $/ \mathrm{cm}^{2}$ can be calculated (see SI). In Fig. 7, the surface concentration for the different alcohols is plotted versus the bulk concentration. From this plot it is clear that the linear alcohols have a higher packing density than the branched alcohols, with a value that is on average $50 \%$ higher. The linear alcohols have values around $2.4 \times 10^{14}$ molecules per $\mathrm{cm}^{2}$, which are in good agreement with previous results, ${ }^{45}$ while the values for the branched alcohols in this study are around $1.6 \times 10^{14}$ molecules per $\mathrm{cm}^{2}$. This difference in the packing density is a result of the molecular orientation at $\mathrm{ML}$ 


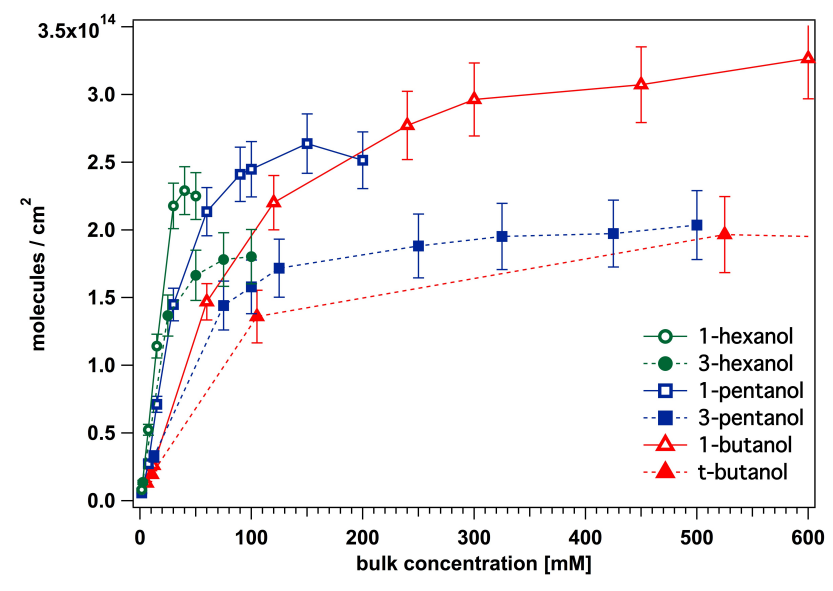

Fig. 7 Surface concentration in molecules $/ \mathrm{cm}^{2}$ for the different alcohols versus the bulk concentration. Error bars correspond to the range of surface concentrations calculated by using a variance in the monolayer thickness by $\pm 0.5 \AA$.

Table 4 Surface concentrations at $\mathrm{ML}$ coverage $\left(\mathrm{C}_{\mathrm{ML}}\right)$ and the maximum surface concentrations calculated for $\mathrm{N}_{\mathrm{s}, \max }\left(\mathrm{C}_{\mathrm{N}(\mathrm{s}, \max )}\right)$ in molecules $/ \mathrm{cm}^{2}$ (for surface concentrations in $\mathrm{mol} / \mathrm{m}^{2}$, see $\mathrm{SI}$ ).

\begin{tabular}{lcc}
\hline molecule & $\mathrm{c}_{\mathrm{ML}}\left(\right.$ molecules $\left./ \mathrm{cm}^{2}\right)$ & $\mathrm{c}_{\mathrm{N}(\mathrm{s}, \max )}\left(\mathrm{molecules} / \mathrm{cm}^{2}\right)$ \\
\hline 1-butanol & $2.5 \times 10^{14}$ & $3.6 \times 10^{14}$ \\
1-pentanol & $2.4 \times 10^{14}$ & $3.3 \times 10^{14}$ \\
1-hexanol & $2.3 \times 10^{14}$ & $3.1 \times 10^{14}$ \\
tert-butanol & $1.5 \times 10^{14}$ & $2.2 \times 10^{14}$ \\
3-pentanol & $1.6 \times 10^{14}$ & $2.2 \times 10^{14}$ \\
3-hexanol & $1.7 \times 10^{14}$ & $2.2 \times 10^{14}$
\end{tabular}

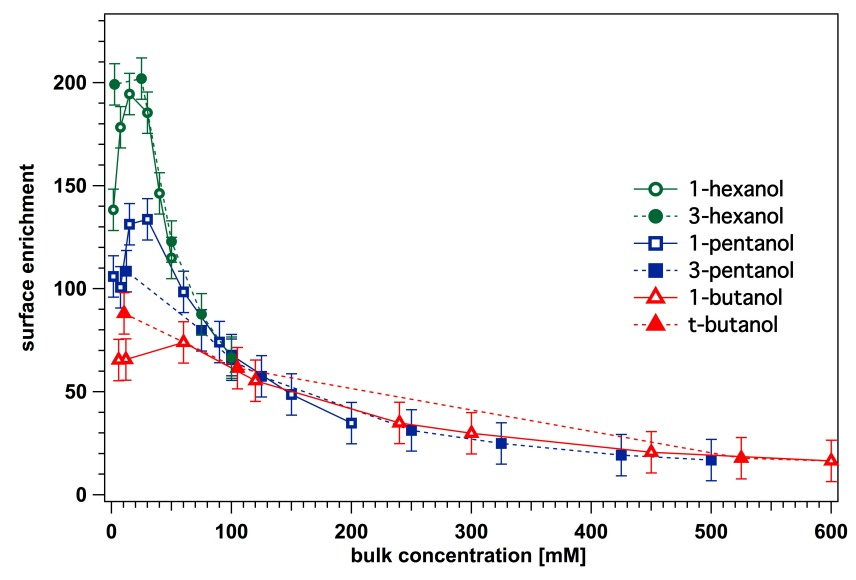

Fig. 8 Surface enrichment factor EF for the different alcohols in aqueous solution versus the bulk concentration. Error bars are estimated from experimental uncertainties.

Table 5 Maximum surface enrichment factors for the primary alcohols

\begin{tabular}{lccc}
\hline molecule & $\mathrm{EF}_{\max }$ & $\mathrm{C}_{\mathrm{EF}(\max )}(\mathrm{mM})$ & $\mathrm{C}_{\mathrm{ML}}(\mathrm{mM})$ \\
\hline 1-butanol & 70 & 60 & 200 \\
1-pentanol & 130 & 30 & 100 \\
1-hexanol & 190 & 15 & 40
\end{tabular}

coverage (where the hydroxyl groups point towards the water and the alkyl parts towards the vacuum) and the different molecular structures (bulkier branched vs. linear alcohols). The surface concentrations in molecules $/ \mathrm{cm}^{2}$ at $\mathrm{ML}$ coverage are summarized in Table 4. For comparison the maximum surface concentrations in molecules $/ \mathrm{cm}^{2}$ for $\mathrm{N}_{\mathrm{s} \text {, max }}$ are given as well (for values in $\mathrm{mol} / \mathrm{m}^{2}$, see $\mathrm{SI}$ ).

\section{Surface enrichment factor}

As mentioned above, there is an overestimation of the surface concentration by the Langmuir model for the primary alcohols at lower concentrations (compare Fig. 3) as a direct result from fitting the surface concentration at higher concentrations more accurately. One aspect that could possibly explain a surface coverage which is lower than expected by the Langmuir model, is a situation where thermodynamic equilibrium has not been established. However, as discussed earlier in more detail, ${ }^{46}$ we concluded from experiments and theoretical considerations that our results are comparable to systems in equilibrium. In fact, a modification of the shape of a Langmuir isotherm can originate from other factors, such as for example attractive lateral interactions between the molecules at the interface, which can result in an S-shape of the isotherm. Here, a two-step adsorption mechanism applies, where in a first step the molecules adsorb as individual molecules and then in a second step, the adsorption increases dramatically as surface aggregates form through interactions of the hydrophobic chains of the surfactant molecules with each other. ${ }^{47}$

In order to explore this phenomenon further, i.e. the deviation of the surface concentration for linear alcohols at lower concentrations in comparison to the Langmuir model, the surface enrichment factor, EF, is determined by calculating the ratio between the molar surface concentration and the molar bulk concentration, i.e. $\mathrm{EF}=\mathrm{c}_{\text {surface }} / \mathrm{c}_{\text {bulk }}$.

In Fig. 8, the enrichment factor EF is plotted versus the respective molar alcohol bulk concentration $c_{\text {bulk }}$. Interestingly, at lower concentrations there is a maximum for the primary alcohols, which peaks at approx. 1/3 of the ML concentration (see Table 5). This maximum is not observed for tert-butanol and 3-pentanol, but seems to start appearing for 3-hexanol. Also, it is noticed that the observed maximum gets more pronounced, i.e. higher, with increasing chain length. Therefore, it is suggested that this maximum in the enrichment factor is connected to the above-mentioned cooperative effect between the alkyl chains based on van der Waals interactions, which increase in magnitude for increasing chain length. These intermolecular forces make it energetically more favorable for the molecules to reside at the interface as soon as there are enough molecules for interaction resulting in island formation. Such van der Waals interactions are more pronounced for linear alcohols than for branched ones, comparing molecules with the same number of carbon atoms, as the part of alkyl chains available for interactions comprise more carbon atoms. Furthermore, the intermolecular distances between linear alcohols should be smaller than in the case of branched alcohols due to steric effects, allowing thus for more efficient van der Waals interactions between the linear alcohols. 
In conclusion, the trend of the surface enrichment factor can be explained as follows: at very low concentrations, the alcohol molecules adsorb individually at the aqueous surface, as enthalpy stabilizes the solutes there; a combination of both water-water and alcohol-water interaction energies was suggested to generate favorable enthalpies for such surface configurations, ${ }^{48}$ explaining the initial surface enrichment factor. With increasing concentration, more and more alcohol molecules adsorb at the interface, which start to interact and form molecular islands. The very efficient van der Waals interactions between linear alcohols become then more important in the energy balance as the surface coverage gets higher, and the surface enrichment factor increases for the linear alcohols compared to the shorter branched alcohols. However, with progressing adsorption at the interface, more and more surface sites are occupied, thus less additional alcohol molecules can reside directly at the interface and the maximum surface coverage is approached. As the surface concentration stays constant but bulk concentration increases further, the surface enrichment factor must then decrease for higher bulk concentrations.

The Langmuir model does not account for attractive lateral interactions between the adsorbed molecules within the surface phase, which is of higher importance for the linear alcohols. If one considers for example 1-hexanol, a Langmuir fit which solely describes the lower concentrations more accurately (up to $30 \mathrm{mM}$ ), a much lower $\Delta \mathrm{G}_{\mathrm{Ads}}$ value of around $-9 \mathrm{~kJ} / \mathrm{mol}$ is determined. However, with this fit $N_{S, \max }$ is significantly overestimated as compared to the experimental data points that saturate at significantly lower values for higher concentrations. By fitting the data points at higher concentrations more accurately, the $\mathrm{N}_{\mathrm{s} \text {, max }}$ value is reasonable and a higher $\Delta \mathrm{G}_{\mathrm{Ads}}$ value of around $-19 \mathrm{~kJ} / \mathrm{mol}$ is estimated. In this case, the Langmuir fit overestimates the surface concentration at lower bulk concentrations, as a result of extrapolating the beneficial van der Waals interactions that are prevalent at higher surface coverage to lower surface coverage, predicting thus higher surface concentrations. Therefore, another consequence of our observations is that the Gibbs free energy of adsorption is dependent on the surface coverage as the molecules are able to interact with each other and can stabilize themselves at the surface. This is in line with the equation that can be applied to approximate the free energy of adsorption of the surfactant for dilute solutions: $\Delta \mathrm{G}_{\mathrm{Ads}}=-R T \log \mathrm{EF}$ (ref. 47) as $\mathrm{EF}$ is changing with concentration. Using the determined $E F$ value for dilute solution, an initial $\Delta \mathrm{G}_{\text {Ads }}$ for 1-hexanol can be estimated to be around $-12 \mathrm{~kJ} / \mathrm{mol}$, which lies between the determined values mentioned above. Thus, with increasing surface coverage, the free energy of adsorption gets more negative as a result of a change in orientation of the molecules allowing for van der Waals interactions between the alkyl chains.

\section{Conclusions}

In this study, we investigated the adsorption of various alcohol isomers with different chain lengths $(\mathrm{C} 4-\mathrm{C} 6)$ at the liquid- vapor interface with surface-sensitive $\mathrm{X}$-ray photoelectron spectroscopy (XPS) and model the data with a standard Langmuir adsorption isotherm to determine Gibbs free energies of adsorption and estimate surface concentrations. From butanol to hexanol, we find $\Delta \mathrm{G}_{\mathrm{Ads}}$ values, which scale linearly from $-15 \mathrm{~kJ} / \mathrm{mol}$ to $-19 \mathrm{~kJ} / \mathrm{mol}$ with a $\Delta \mathrm{G}_{\text {Ads }}$ per $-\mathrm{CH}_{2}-$ value of $-2 \mathrm{~kJ} / \mathrm{mol}$. The $\Delta G_{\text {Ads }}$ values for the linear alcohols are slightly more negative than the values determined for the branched alcohols, which is in line with their higher surface concentrations. At monolayer coverage, the surface concentrations of the linear alcohols are around $2.4 \times 10^{14}$ molecules $/ \mathrm{cm}^{2}$, while the branched alcohols in this study have values around $1.6 \times 10^{14}$ molecules $/ \mathrm{cm}^{2}$. Thus, the packing density of the primary alcohols at $\mathrm{ML}$ coverage is on average $50 \%$ higher than the one of the branched alcohols, which is consistent with the molecular structures and their orientation at the interface. Most interestingly, we find that the surface enrichment factor for the linear alcohols has a maximum at lower concentrations, which is not observed for the shorter branched alcohols. This is interpreted as a cooperative effect between the linear alcohols, which makes it energetically more favorable to reside at the aqueous surface as soon as there is a sufficient amount of molecules at the interface allowing for van der Waals interactions between the alkyl chains and thus the formation of islands.

Different oxidation pathways in the atmosphere can lead to the formation of different isomers of the oxidation products for a given organic precursor. We see here, that depending on which isomers are formed and eventually end up in the condensed aerosol phase will affect the surface structural properties of aqueous aerosols. The impact of this on e.g. cloud microphysics is of interest for further investigations.

\section{Acknowledgements}

Financial support from the Swedish Research Council (VR), Swedish Foundation for Strategic Research, NICITA and the Carl Tryggers Stiftelse för Vetenskaplig Forskning (M.-M. W.) is gratefully acknowledged. NPL gratefully acknowledges the personal funding received from the Carlsberg Foundation (grants 2009_01_0366 and 2010_01_0391) and the Finnish Academy of Sciences (257411). MAX IV Laboratory, Lund University, Sweden, is acknowledged for the allocation of beamtime and laboratory facilities. Dr. Daniel Lundberg is acknowledged for discussion and proof-reading.

\section{Notes and references}

1 N. M. Donahue, A. L. Robinson, C. O. Stanier and S. N. Pandis, Environ. Sci. Technol., 2006, 40, 2635.

2 M. Hallquist, J. C. Wenger, U. Baltensperger, Y. Rudich, D. Simpson, M. Claeys, J. Dommen, N. M. Donahue, C. George, A. H. Goldstein, J. F. Hamilton, H. Herrmann, T. Hoffmann, Y. linuma, M. Jang, M. E. Jenkin, J. L. Jimenez, A. KiendlerScharr, W. Maenhaut, G. McFiggans, Th. F. Mentel, A. Monod, A. S. H. Prévôt, J. H. Seinfeld, J. D. Surratt, R. Szmigielski and J. Wildt, Atmos. Chem. Phys., 2009, 9, 5155. 
3 N. M. Donahue, G. T. Drozd, S. A. Epstein, A. A. Presto and J. H. Krol, Phys. Chem. Chem. Phys., 2011, 13, 10848.

4 R. K. Pathak, K. Salo, E. U. Emanuelsson, C. Cai, A. Lutz, Å. M. Hallquist and M. Hallquist, Environ. Sci. Technol., 2012, 46, 11660.

5 N. M. Donahue, S. A. Epstein, S. N. Pandis and A. L. Robinson, Atmos. Chem. Phys., 2011, 11, 3303.

6 D. Koch and A. D. Del Genio, Atmos. Chem. Phys., 2010, 10 7685.

7 IPCC, Climate change 2013, The physical science basis, Cambrige University Press, 2013, ISBN 978-1-107-66182-0.

8 N. L. Prisle, N. Ottosson, G. Öhrwall, J. Söderström, M. Dal Maso and O. Björneholm, Atmos. Chem. Phys., 2012, 12, 12227.

9 H. Singh, Y. Chen, A. Staudt, D. Jacob, D. Blake, B. Heikes and J. Snow, Nature, 2001, 410, 1078.

10 S. V. Glass, S.-C. Park and G. M. Nathanson, J. Phys. Chem. A, 2006, 110, 7593

11 J. Sung, K. Park and D. Kim, J. Phys. Chem. B, 2005, 109, 18507.

12 M. Ehn, J. A. Thornton, E. Kleist, M. Sipilä, H. Junninen, I. Pullinen, M. Springer, F. Rubach, R. Tillmann, B. Lee, F. Lopez-Hilfiker, S. Andres, I.-H. Acir, M. Rissanen, R. Jokinen, S. Schobesberger, J. Kangasluoma, J. Kontkanen, T. Nieminen, T. Kurtén, L. B. Nielsen, S. Jorgensen, H. G. Kjaergaard, M. Canagaratna, M. Dal Maso, T. Berndt, T. Petäjä, A. Wahner, V.-M. Kerminen, M. Kulmala, D. R. Worsnop, J. Wildt and T. F. Mentel, Nature, 2014, 506, 476.

13 P. Lin, A. G. Rincon, M. Kalberer and J. Z. Yu, Environ. Sci. Technol., 2012, 46, 7454.

14 J. Glinski, G. Chavepeyer, J.-K. Platten and P. Smet, J. Chem. Phys., 1998, 109, 5050.

15 S. Z. Can, D. D. Mago, O. Esenturk and R. A. Walker, J. Phys. Chem. C., 2007, 111, 8739.

16 N. Ottosson, E. Wernersson, J. Söderström, W. Pokapanich, S. Kaufmann, S. Svensson, I. Persson, G. Öhrwall and O. Björneholm, Phys. Chem. Chem. Phys., 2011, 13, 12261.

17 Y. Jung and R. A. Marcus, J. Am. Chem. Soc., 2007, 129, 5492.

18 O. Acevedo and K. Armacost, J. Am. Chem. Soc., 2010, 132, 1966.

19 K.R. Wilson, R.D. Schaller, B.S. Rude, T. Catalano, D.T. Co, J.D. Bozek, and R.J. Saykally, J. Chem. Phys., 2002, 117, 7738.

20 M. Bilde, B. Svenningsson, J. Monster and T. Rosenorn, Environ. Sci. Technol., 2003, 37, 1371

21 Y.-H. Lin, Z. Zhang, K. S. Docherty, H. Zhang, S. Hapsari Budisulistiorini, C. L. Rubitschun, S. L. Shaw, E. M. Knipping, E. S. Edgerton, T. E. Kleindienst, A. Gold and J. D. Surratt, Environ. Sci. Technol., 2012, 46, 250.

22 C. R. Ruehl, T. Nah, G. Isaacman, D. R. Worton, A. W. H. Chan, K. R. Kolesar, C. D. Cappa, A. H. Goldstein and K. R. Wilson, J. Phys. Chem. A, 2013, 117, 3990.

23 B. L. J. Poad, H. T. Pham, M. C. Thomas, J. R. Nealon, J. L. Campbell, T. W. Mitchell and S. J. Blanksby, J. Am. Soc. Mass Spectrom., 2010, 21, 1989.

24 C. Fan, S. Pu, G. Liu and T. Yang, J. Photochem. Photobio. A, 2008, 197, 415.

25 M. Bässler, A. Ausmees, M. Jurvansuu, R. Feifel, J.O. Forsell, P. de Tarso Fonseca, A. Kivimäki, S. Sundin, S.L. Sorensen, R. Nyholm, O. Björneholm, S. Aksela and S. Svensson, Nucl. Instrum. Methods Phys. Res. Sect. A, 2001, 469, 382.

26 B. Winter and M. Faubel, Chem. Rev., 2006, 106, 1176.

27 S. Hüfner, Photoelectron Spectroscopy, Springer Verlag, Berlin, 1995.

28 B. Winter, R. Weber, W. Widdra, M. Dittmar, M. Faubel and I.V. Hertel, J. Phys. Chem. A, 2005, 184, 2625.

29 N. Preissler, F. Buchner, T. Schultz and A. Lübcke, J. Phys. Chem. B, 2013, 117, 2422.
30 H. Nikjoo, S. Uehara, D. Emfietzoglou and A. Brahme, New J. Phys., 2008, 10, 075006.

31 Y.-I. Suzuki, K. Nishizawa, N. Kurahashi and T. Suzuki, Phys. Rev. E, 2014, 90, 010302(R).

32 P. van der Straten, R. Morgenstern and A. Niehaus, Z. Phys. $D, 1988,8,35$.

33 J. L. Campbell and T. Papp, Atom. Data Nucl. Data Tables, 2001, 77, 1.

34 N. Ottosson, K. J. Børve, D. Spångberg, L. J. Sæthre, M. Faubel, H. Bergersen, W. Pokapanich, G. Öhrwall, O. Björneholm and B. Winter, J. Am. Chem. Soc., 2011, 133, 3120.

35 M.-M. Walz, C. Caleman, J. Werner, V. Ekholm, D. Lundberg, N. L. Prisle, G. Öhrwall and O. Björneholm, Phys. Chem. Chem. Phys., 2015, 17, 14036.

36 A. W. Adamson and A. P. Gast, Physical Chemistry of Surfaces, Wiley, New York, $6^{\text {th }}$ edn, 1997.

37 B. Minofar, P. Jungwirth, M. R. Das, W. Kunz and S. J. Mahiuddin, J. Phys. Chem. C, 2007, 111, 8242.

38 O. Björneholm, J. Werner, N. Ottosson, G. Öhrwall, V. Ekholm, B. Winter, I. Unger and J. Söderström, J. Phys. Chem. C, 2014, 118, 29333.

39 R. M. Onorato, D. E. Otten and R. J. Saykally, PNAS, 2009, 106, 15176

40 P. B. Petersen and R. J. Saykally, Chem. Phys. Lett., 2004, 397 51.

41 K. A. Perrine, M. H. C. van Spyk, A. M. Margarella, B. Winter, M. Faubel, H. Bluhm and J. C. Hemminger, J. Phys. Chem. C., 2014, 118, 29378.

42 K. D. Danov and P. A. Kralchevsky, Colloid Journal, 2012, 74, 172.

43 A. Naves De Brito, R. R. T. Marinho, M.-M. Walz and O. Björneholm , publication in preparation.

44 A. Chodzinska, A. Zdziennicka, and B. Janczuk, J. Solution Chem., 2012, 41, 2226.

45 A. Firooz and P. Chen, J. Colloid Interface Sci., 2012, 370, 183.

46 G. Öhrwall, N. L. Prisle, N. Ottosson, J. Werner, V. Ekholm, M.-M. Walz and O. Björneholm, J. Phys. Chem. B, 2015, 119, 4033.

47 M. J. Rosen, Surfactants and interfacial phenomena, WileyInterscience, $3^{\text {rd }}$ edn, 2004.

48 J. S. Hub, C. Caleman and D. van der Spoel, Phys. Chem. Chem. Phys., 2012, 14, 9537. 